\title{
Paraneoplastic and Idiopathic Ganglionopathy: Importance of Differential Diagnosis
}

Guilherme Perassa Gasque*, Felipe da Rocha Schmidt, Diogo Matheus Terrana de Carvalho, Salim Balassiano, José Marcelo Ferreira Bezerra and Marcia Rodrigues Jardim

Department of Neurology, Pedro Ernesto University Hospital, State University of Rio de Janeiro (UERJ), Rio de Janeiro, RJ, Brazil

*Corresponding author: Guilherme Perassa Gasque, Department of Neurology, Pedro Ernesto University Hospital, State University of Rio de Janeiro (UERJ), Rio de Janeiro, RJ, Brazil, Tel: +552123340639; E-mail: guigasque_4@hotmail.com

Received date: Nov 10, 2015; Accepted date: Dec 11, 2015; Published date: Dec 18, 2015

Copyright: $\odot 2015$ Gasque GP, et al. This is an open-access article distributed under the terms of the Creative Commons Attribution License, which permits unrestricted use, distribution, and reproduction in any medium, provided the original author and source are credited.

\begin{abstract}
Sensory ganglionopathies (SG) may occur in association with different diseases and are characterized by the degeneration of the primary sensory neurons located in the dorsal root ganglia. The most important associated conditions are paraneoplastic SG, HIV infection, Sjogren's syndrome, and cisplatin or pyridoxine toxicity. Even when clinical criteria help differentiate SG from other neuropathies, an etiological diagnosis remains elusive. Thus, there is a need to identify biological markers than can distinguish immune-mediated SG from other etiologies. Objectives: The present study of two cases of SG compares their neurological outcomes with their treatment responses in accordance with the etiology of each one. Methods: evaluate the clinical presentation and examination results to be able to define the etiology and institute early treatment. Results: To differentiate paraneoplastic and idiopathic causes, more precise imaging techniques and paraneoplastic antibody tests are required. These diagnostic tools might be helpful in early diagnosis and treatment, thus affording the best chance of stabilizing the neurological symptoms. Conclusions: The identification of paraneoplastic antibodies before the onset of cancer can reduce the percentage of cases misdiagnosed as idiopathic, leading to early treatment and perhaps a more favorable prognosis.
\end{abstract}

Keywords: Multiple sclerosis; Cognitive impairment; Tunisia

\section{Introduction}

Sensory ganglionopathies (SG), characterized by the degeneration of the primary sensory neurons located in the dorsal root ganglia, may occur in association with different diseases [1]. The most important associated conditions are paraneoplastic SG, HIV infection, Sjogren's syndrome, and cisplatin or pyridoxine toxicity [2]. Half of all cases are still labeled idiopathic. The sensory deficits are usually multifocal, involving the proximal and distal parts of the limbs; and all sensory modalities - pain, temperature, sense position, and vibration - may be compromised during the course of the disease [1,3]. Gait ataxia and widespread arreflexia often occur $[1,3,4]$. Some patients have pseudoathetotic hand movements. Injury to small and medium-sized neurons can generate pain, a burning sensation, and allodynia $[1,3,4]$ while the motor system examination is usually unremarkable. Nystagmus is not frequent, but autonomic dysfunction may be found. There have been reports of tonic pupils, orthostatic hypotension, gastrointestinal symptoms, and erectile dysfunction.

Nerve conduction studies are the most useful tests in evaluating SG $[3,5]$. The distinguishing characteristics between SG and other sensory neuropathies are important to properly focus the etiological investigation and the adoption of appropriate treatment [2]. However, the diagnosis of SG is often challenging for the practicing neurologist. Furthermore, there is evidence that, in some cases, the dorsal root ganglia and peripheral nerves can be affected simultaneously such as in Sjögren's syndrome [6]. Thus, reliable diagnostic criteria for SG are urgently needed as a backdrop in clinical practice [6]. Even when clinical criteria aid in differentiating SG from other neuropathies, an etiological diagnosis remains elusive. Thus, there is a need for biological markers than can distinguish immune-mediated SG from other etiologies [7].

Other tests, such as screening for occult tumors and searching for paraneoplastic antibodies are essential for the establishment of an etiological diagnosis since paraneoplastic SG may precede the tumor within five years of diagnosis [8].

The present study examines two cases of SG by comparing and highlighting the importance of the clinical presentation and laboratory results mainly from the perspective of the presence of paraneoplastic antibodies in the management of patients.

\section{Case Report}

\section{Case 1}

A $49 y$, single, mixed-race female and small business owner and resident of Rio de Janeiro was admitted to the Pedro Ernesto University Hospital in Rio de Janeiro, Brazil, due to hand paresthesias and cooking difficulties that, within a month, evolved into involuntary movements of the hands and numbness in the forearms and feet. He smoked a pack a day for 20 years and drank alcohol regularly. She was then taking $25 \mathrm{mg} /$ day amitriptyline. The physical examination showed the patient to be in generally good health and pale $1+/ 4+$. The neurological examination showed sensory ataxic gait and a Romberg sign, along with widespread areflexia, dysmetria, and dysdiadocokinesia in the upper limbs (UL) that worsened with eye closure, bilateral flexor plantar responses, tactile hypoesthesia, painful asymmetric and multifocal, apalesthesia, and loss of proprioception distal limbs and pseudoathetosis movements in the hands. He also 
Citation: Gasque GP, da Rocha SF, de Carvalho DMT, Balassiano S, Bezerra JMF, et al. (2015) Paraneoplastic and Idiopathic Ganglionopathy: Importance of Differential Diagnosis . J Neurol Neurophysiol 6: 1000339. doi:10.4172/2155-9562.1000339

Page 2 of 4

presented signs and symptoms of dysautonomia: tonic pupils, postural hypotension, constipation, and postprandial fullness.

\section{Case 2}

As of January 2012, a 41y, previously healthy, white, married, righthanded woman, who was a telecommunications technician living in the City of Campo Grande in the State of Rio de Janeiro, began feeling a choking sensation in the first, second and third fingers of the right hand and "inflexibility" in the right forearm, all of which worsened over the next four months, when she started feeling a tingling sensation in her left hand. While the symptoms spontaneously resolved in the right forearm, there was no improvement in the paresthesias in both hands. After a year, she complained of bilateral) "heaviness" in her legs and numbness up to the knees. Neurological examination revealed an ataxic gait, Romberg sign, and dysmetry in the UL and lower limbs (LL). Strength and tone were normal and diffuse areflexia and indifferent flexor reponses were found. There was tactile and painful hypoesthesia and hypopalestesia in the hands, which was worse in the right hand, accompanied by pseudoathetosis movements in both hands, again worse in the right. However, the cranial nerves presented no abnormalities.

In both reports, the patients had an abnormal neurological examination compatible with a SG. In the first case, there were associated signs and symptoms of dysautonomia. Thus, we began by the etiological investigation of these cases. See Tables 1 and 2 below.

\begin{tabular}{|l|l|l|}
\hline Features & Case 1 & Case 2 \\
\hline Gender & Female & Female \\
\hline Age & 41 years & 49 years \\
\hline Onset of symptoms & Hands & Hands \\
\hline Sensory deficit & Anesthesia in limbs & Sensory ataxia \\
\hline $\begin{array}{l}\text { Sensory deficit in the face and } \\
\text { trunk }\end{array}$ & Yes & No \\
\hline Sensory standard & Non-length-dependent & $\begin{array}{l}\text { Non-length- } \\
\text { dependent }\end{array}$ \\
\hline Evolution & Subacute (<6months) & Chronic (> 3years) \\
\hline Gait & Ataxic & Ataxic \\
\hline Deep reflexes & Absent & Absent \\
\hline Neuropathic pain & Yes & No \\
\hline Pseudoathetosis in hands & Yes & Yes \\
\hline Dysautonomia & Yes & No \\
\hline
\end{tabular}

Table 1: comparing the clinical characteristics of patients reported

\begin{tabular}{|c|c|c|}
\hline Exams & Patient 1 & Patient 2 \\
\hline Blood count, renal function, liver, and thyroid & Normal & Normal \\
\hline HIV, syphilis, and hepatitis A, B and C & Negative & Negative \\
\hline HTLV 1 and 2 & Negative & Negative \\
\hline LES, Sjogren, celiac disease & Negative & Negative \\
\hline VHS, complement & Normal & Normal \\
\hline Vitamin B12, folic acid & Normal & Normal \\
\hline Serum copper and Vitamin E & Normal & Normal \\
\hline Protein electrophoresis & Normal & Normal \\
\hline CEA, CA 125 e CA 19-9 & Normal & Normal \\
\hline Nerve Conduction Studies & $\begin{array}{l}\text { Sensory conduction absence in all four limbs. Normal } \\
\text { motor conduction }\end{array}$ & $\begin{array}{l}\text { Sensory conduction absence in all four limbs. Normal } \\
\text { motor conduction }\end{array}$ \\
\hline CSF & leucocytes: 4, Glucose: 70 , protein $76.9 \mathrm{mg} / \mathrm{dl}$ & Leukocyte $<1,=67$ glucose, protein $=30.3 \mathrm{mg} / \mathrm{dl}$ \\
\hline CT chest, abdomen, and pelvis & $\begin{array}{l}\text { Pulmonary nodule in the right lower lobe and paratracheal } \\
\text { lymph node }\end{array}$ & Normal \\
\hline RM skull and marrow & Normal & $\begin{array}{l}\text { Hyperintense on T2 and STIR in posterior cord of the } \\
\text { cervical and thoracic spine }\end{array}$ \\
\hline Paraneoplastic antibodies & Anti-Hu + & negative \\
\hline Pet Scan & Unrealized & Normal \\
\hline
\end{tabular}

Table 2: Comparison of Laboratory Results

The paraneoplastic antibodies were surveyed: anti-Hu, anti-Yo, anti-

$\mathrm{Ri}$, Anti-CV2, Anti- Ma2, and anti- anfifisina. 
The first patient underwent a biopsy of the lung and paratracheal lymph nodes; the histopathology report was undifferentiated small-cell neuroendocrine carcinoma (oat cell).

\section{Discussion}

Whereas SG is traditionally considered a rare disorder, underdiagnosis is certainly a problem $[3,4]$. The most important causes are: paraneoplastic, secondary to HIV infection and autoimmune disorders, cisplatin and pyridoxine toxicity, and idiopathic cases [2]. Sjogren's syndrome (SS) is the most frequent immune-mediated disease related to SG [2]. Some authors estimate that $10 \%$ of all patients with SS will ultimately develop an SG. Unfortunately, 50\% of all SG cases are still labeled idiopathic [3,9]. SG is the most frequent paraneoplastic syndrome, representing around 20\% of all paraneoplasias according to the European study "Paraneoplastic neurologic syndrome in the PNS euronetwork database: a European study from 20 centers" $[3,8,18]$. The paraneoplastic etiology for SG is confirmed in about $20 \%$ patients $[10,11]$. The strongest association is with lung cancer, small-cell typically $70 \%-80 \%$, but other associated tumors include breast and ovarian cancer, sarcoma, and Hodgkin's lymphoma [10-13]. According to Sarah Sheikh and Anthony Amato (2010), the average time span between the onset of SG and the diagnosis of cancer is five months, ranging anywhere from a few weeks to about five years. Early detection and treatment of the underlying neoplasm seem to offer the best chance of stabilizing the neurological symptoms $[13,14]$. It is, therefore, necessary to first evaluate the clinical presentation and laboratory results in order to define the etiology before instituting early treatment.

After extensive etiological investigation, case 1 was diagnosed with paraneoplastic SG in conjunction with autonomic features secondary to oat-cell lung cancer, in confirmation of published data. He was initially treated with high-dose intravenous methylprednisolone followed by intravenous immunoglobulin. But, as sensory complaints intensified, sudden episodes of pain in the face, neck and limbs also appeared. The neurological symptoms improved after the identification and treatment of lung cancer with etoposide and cisplatin. Nevertheless, after 11 months, the patient had respiratory failure due to lung-tumor complications and died.

The search for paraneoplastic antibodies was fundamental in reaching an etiologic diagnosis in this case, in which the neurological symptoms improved only after the onset of specific treatment. The most frequently found paraneoplastic antibody is the Anti-Hu or ANNA1, with $99 \%$ specificity and $82 \%$ sensitivity [12-15]. This antibody is usually associated with oat-cell lung cancer. The absence of this antibody does not exclude an underlying cancer, however. Other antibodies that might be associated with SG are: anti Yo, anti-CV2, anti-PNMA2, anti-MA1, anti-amphyphysin, and anti-CRMP-5.

According to Sheikh and Amato (2010), the usual pattern detected in the sensory nerve conduction studies related to SG is a non-lengthdependent sensory neuropathy with a marked reduction in amplitudes or a diffuse absence of action potentials in the sensory nerves (SNAPs). This pattern characterizes the distinction between SG and polyneuropathy with retrograde axonal death in which a distalproximal gradient is common featuring a length-dependent sensory deficit. The motor conduction studies are usually normal. However, at times, there is a mild reduction in the amplitudes of the compound muscle action potential (CMAPs), especially in patients with paraneoplastic SG [8]. In case 1 (paraneoplastic SG), for example, reduced amplitudes in the motor nerves of the lower limbs were found. This is in line with Lauria et al. (2003), who showed abnormalities in motor nerve conduction, which were most frequent in the lower limbs in paraneoplastic cases.

As seen in case 2, magnetic resonance imaging (MRI) of the cervical and thoracic spine is useful in attempting to demonstrate any central involvement [8]. As this change takes some time to develop, it is usually seen in chronic SG. The MRI typically shows T2 hyperintensities in the dorsal columns of the spinal cord, which is the neuroradiological correlate of large myelinated sensory fibre degeneration due to damage to the dorsal root ganglion cells, as has been confirmed in pathological studies [8].

In accordance with previous data, these cases demonstrate that the clinical course can also be useful in distinguishing between autoimmune / idiopathic and paraneoplastic. The chronic course is more common in idiopathic circumstances while an abrupt onset is usually seen in paraneoplastic or autoimmune etiologies $[1,3,6]$. An acute or subacute evolution together with an inflammatory profile in the cerebrospinal fluid (CSF) strongly argue for a paraneoplastic origin while chronic course and normal CSF results support the hypothesis regarding idiopathic cases $[12,16,17]$. In case 1 , the patient underwent a subacute evolution and an inflammatory CSF with a confirmed paraneoplastic etiology. In contrast, the case 2 patient followed a chronic course with a normal CSF normal and an unestablished etiology.

Case 2 remained an idiopathic SG even after an extensive complementary work-up. However, the annual repetition of the imaging for a consecutive period of five years is required. If after this period, all examinations remain negative, the etiological diagnosis will be confirmed as idiopathic. Treatment of patient 2 was performed with intravenous immunoglobulin. The result was improved paresthesias in the lower limbs but only a slight improvement in sensory ataxia. The patient continues performing intravenous immunoglobulin cycles every three months with additional improvement of ataxia. The disease has been slowly progressing over the last three years even though the patient is still responding to periodic immunoglobulin infusions. The autoantibodies that are reactive to the sensory neurons identified in paraneoplastic SG are well known as biological markers capable of distinguishing immune-mediated SG from other aetiologies [7]. Antoine JC et al (2015) have recently described the diagnostic accuracy of serum antibodies against the intracellular domains of fibroblast growth factor receptor 3 (FGFR3; anti-FGFR3 Abs) to identify a patient subgroup that has developed a sensory neuron disorder, which suggests that in the future other immune markers could be detected in patients that initially appear to have idiopathic SG.

After identifying SG by way of clinical and neurophysiological criteria, an etiological diagnosis can present a challenge, as previously mentioned. A differential diagnosis includes treatable causes such as metabolic disorders both toxic and autoimmune. However, paraneoplastic causes might even be more difficult to recognize. In such cases, more precise imaging techniques and tests to detect the presence of paraneoplastic antibodies are needed. As seen in our first patient, these diagnostic tools might help reach an accurate diagnosis and lead to early treatment with the best chance of stabilizing the neurological symptoms. Thus, identification of paraneoplastic antibodies before the onset of cancer can reduce the percentage of cases misdiagnosed as idiopathic, opening the way for early treatment and perhaps a more favorable prognosis. 
Citation: Gasque GP, da Rocha SF, de Carvalho DMT, Balassiano S, Bezerra JMF, et al. (2015) Paraneoplastic and Idiopathic Ganglionopathy: Importance of Differential Diagnosis . J Neurol Neurophysiol 6: 1000339. doi:10.4172/2155-9562.1000339

Page 4 of 4

\section{References}

1. Kuntzer T, Antoine JC, Steck AJ (2004) Clinical features and pathophysiological basis of sensory neuronopathies ganglionopathies. Muscle Nerve 30: 255-268.

2. Antoine JC, Robert-Varvat F, Maisonobe T, Créange A, Franques J, et al (2014) Testing the validity of a set of diagnostic criteria for sensory neuronopathies: a francophone collaborative study. J Neurol 261: 2093-2100.

3. Martinez ARM, Nunes MB, Nucci A, França MC (2012) Sensory Neuronopathy and Autoimmune Diseases, Autoimmune Diseases.

4. Damasceno A, França MC Jr, Nucci A (2008) Chronic acquired sensory neuron diseases. Eur J Neurol 15: 1400-1405.

5. Lauria G, Pareyson D, Sghirlanzoni A (2003) Neurophysiological Diagnosis of Acquired Sensory Ganglionopathies, Eur Neurol 50:146152.

6. Camdessanché JP, Jousserand G, Ferraud K, Vial C, Petiot P, et al. (2009) The pattern and diagnostic criteria of sensory neuronopathy: a casecontrol study. Brain 132: 1723-1733.

7. Antoine JC, Boutahar N, Lassablière F, Reynaud E, Ferraud K, et al. (2015) Antifibroblast growth factor receptor 3 antibodies identify a subgroup of patients with sensory neuropathy, J Neurol Neurosurg Psychiatry 86: 1347-55.

8. Sheikh SI, Amato AA (2010) The dorsal root ganglion under attack: the acquired sensory ganglionopathies, Pract Neurol 10: 326-334.

9. Gøransson LG, Herigstad A, Tjensvoll AB, Harboe E, Mellgren SI, et al (2006) Peripheral neuropathy in primary sjogren syndrome: a population-based study. Arch Neurol 63: 1612-1615.
10. Chalk CH, Windebank AJ, Kimmel DW, McManis PG (1992) The distinctive clinical features of paraneoplastic sensory neuronopathy. Can J Neurol Sci 19: 346-351.

11. Horwich MS, Cho L, Porro RS, Posner JB (1977) Subacute sensory neuropathy: a remote effect of carcinoma. Ann Neurol 2: 7-19.

12. Graus F, Keime-Guibert F, Reñe R, Benyahia B, Ribalta T, et al. (2001) Anti-Hu-associated paraneoplastic encephalomyelitis: analysis of 200 patients. Brain 124: 1138-1148.

13. Sillevis Smitt P, Grefkens J, de Leeuw B, van den Bent M, van Putten W, et al. (2002) Survival and outcome in 73 anti-Hu positive patients with paraneoplastic encephalomyelitis/sensory neuronopathy. J Neurol 249: 745-753.

14. Keime-Guibert F, Graus F, Broët P, Reñé R, Molinuevo JL, et al. (1999) Clinical outcome of patients with anti-Hu-associated encephalomyelitis after treatment of the tumor. Neurology 53:1719-1723.

15. Molinuevo JL, Graus F, Serrano C, Reñe R, Guerrero A, et al. (1998) Utility of anti-Hu antibodies in the diagnosis of paraneoplastic sensory neuropathy. Ann Neurol 44: 976-980.

16. Dalakas MC (1986) Chronic idiopathic ataxic neuropathy. Ann Neurol 19: 545-554.

17. Chalk CH, Windebank AJ, Kimmel DW, McManis PG (1992) The distinctive clinical features of paraneoplastic sensory neuronopathy. Can J Neurol Sci 19: 346-351.

18. Giometto B, Grisold W, Vitaliani R, Graus F, Honnorat J, et al. (2010) Paraneoplastic neurologic syndrome in the PNS euronetwork database: a European study from 20 centers, Arch Neurol 67: 330-335. 